Using exploratory factor analysis to explore personal attitudes influencing the peopleplant relationship in Danish workplaces

Thomsen, Jane Dyrhauge; H K K, Sønderstrup-Andersen; Müller, Renate

Publication date:

2010

Document version

Publisher's PDF, also known as Version of record

Citation for published version (APA):

Thomsen, J. D., H K K, S-A., \& Müller, R. (2010). Using exploratory factor analysis to explore personal attitudes influencing the people-plant relationship in Danish workplaces. Poster session presented at 28th International Horticultural Congress, Lissabon, Portugal. 


\section{Using Exploratory Factor Analysis to Explore Personal Attitudes Influencing the People-Plant Relationships in Danish Workplaces}

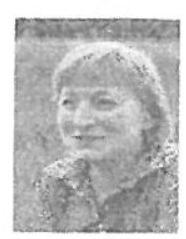

$\underline{\text { Jane D. Thomsen }}{ }^{1}$, Hans K. K. Sønderstrup-Andersen ${ }^{2}$ and Renate Müller ${ }^{1}$

'Department of Agriculture and Ecology, Faculty of Life Sclences, University of Copenhagen, Denmark, Jdt@.life.ku.dk, 2Department of Psychology and Educational studies, Roskilde, University, Denmark

\section{Main findings}

The results indicate that personal attitude towards ornamental plants are related to the perceived benefits of having ornamental plants in office work environments

Based on the answers of 37 Danish employees on 13 items regarding their attitudes towards ornamental plants in office workplaces an exploratory factor analysis (EFA) revealed that the items could be summarized in two factors (figure 1 and 2). Factor 1 concerned whether ornamental plants were wanted in the workplace or not whereas factor 2 concerned percelved benefits of having ornamental plants in the workplace in relation to the employees' general well-being (figure 2).

In conclusion the results presented here form an interesting platform from which the question of how personal attitudes are affecting people-plants relationships in Danish office workplaces can be investigated. Therefore we are planning to conduct further studies.

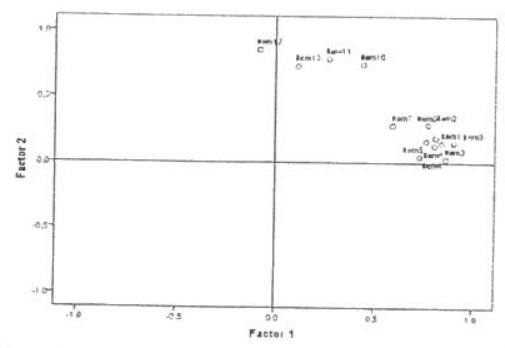

Figure 1: Component plot in rotated space of the scale measuring attitudes towards ornamental plants at the workplace. Factor 1: wanting
perceived benefits of having plants.

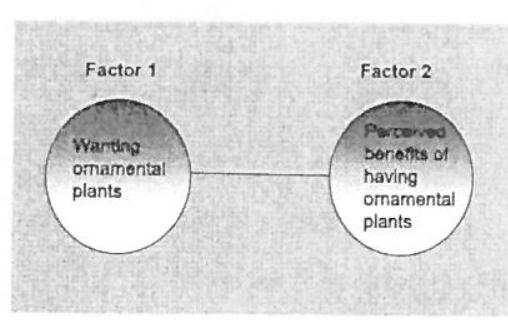

Figure 2: Constructs measured by the two factors extracted by the EFA

\section{Material and methods}

The material upon which the EFA was performed was collected with a questionnaire developed in relation to a larger qualitative case-study exploring people-plant relationships at Danish office workplaces (Thomsen and Müller, in press). Apart from demographical questions the questionnaire contained a scale composed of 13 items regarding attitudes and views of ornamental plants at the workplace (figure 3 ).

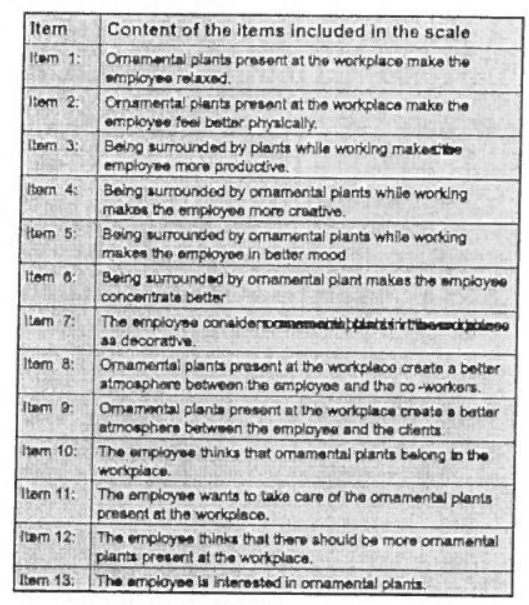

Flgure 3: Items included in the scale. The items are constructed on the basis of expert analysis of subject field combined with a review of existing literature about people-plant relationships in offices.
The items were formulated as statements to which the respondents had to state to which extent they agreed. The possible answers were built around a 5-point Likert scale ranged from "not at all" to "a very high extent" (figure 4).

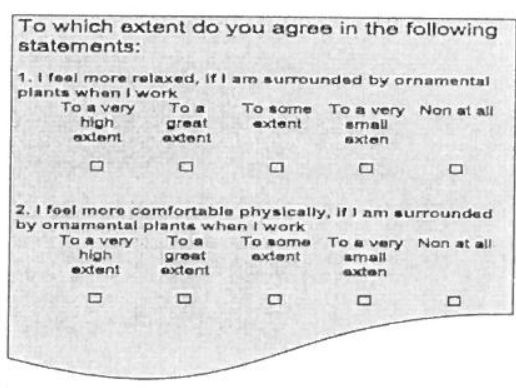

Figure 4: Examples of how items were formulated in the questionnaire.

The EFA was conducted using the statistical software: SPSS version 18. The EFA was performed using principle component analysis (PCA), Kaiser criterion and the orthogonal rotation technique: varimax. The labelling of the extracted factors was based our fundamental understanding of the topic covered by the items (figure 2). Also, Cornbach's Alpha coefficients were calculated in order to investigate the reliability of the factors extracted.

\section{Results}

Two factors were found: one consisted of item 10, 11, 12 and 13 and labelled "wanting plants; the other factor consisted of factor 1 , $2,3,4,5,6,7,8$ and 9 and labelled perceived benefits of having plants (figure 1 and 2). The Cornbach's alpha coefficients were 0.79 for factor 1 and 0.93 for factor 2 .

References

Thoomsen, J. D., and Moller, R. (in press): Plants for a better life -
people-plant relartionships in Indoor work environments. Acta 